\title{
Health Scope
}

\section{Insecticide Resistance in Insect Vectors of Disease with Special Reference to Mosquitoes: A Potential Threat to Global Public Health}

\author{
Kaliyaperumal Karunamoorthi ${ }^{1,2^{*}}$, Shanmugavelu Sabesan ${ }^{3}$ \\ ${ }^{1}$ Department of Environmental Health Sciences, Unit of Medical Entomology and Vector Control, College of Public Health and Medical Sciences, Jimma \\ University, Ethiopia, India \\ ${ }^{2}$ Research and Development Centre, Bharathiar University, Coimbatore, Tamil Nadu, India \\ ${ }^{3}$ Vector Control Research Centre (Indian Council of Medical Research), Indira Nagar, Pondicherry, India
}

${ }^{*}$ Corresponding author Kaliyaperumal Karunamoorthi, Department of Environmental Health Sciences, Unit of Medical Entomology and Vector Control, College of Public Health and Medical Sciences, Jimma University, Ethiopia, India. Tel.:+251-93547847, Fax:+251-0471111450, E-mail:k_karunamoorthi@yahoo.com.

\begin{abstract}
A B S T R A C T
Context: Arthropod-borne diseases are remaining as a major public health issue in the resource-constrained settings. Mosquitoes are closely associated with mankind since time immemorial and play an important role in the transmission of many dreadful diseases like malaria, filariasis, Japanese encephalitis, dengue and yellow fever. Over the decades, vector control is an important element to minimize the vector-borne disease burden worldwide and in fact, it heavily relies upon synthetic insecticides as a mainstay. However the overuse and misuse of insecticides have led to the emergence of resistance, which undermines the potentiality of vector control.

Evidence Acquisition: In order to pursue effective research pertained to this issue, a detailed search on Scopus, Medline, Google Scholar and academic premier databases has been conducted between the time periods of 1955 and 2012 .

Results: Over the pastsixdecades, insecticides are serving as one of the importantarsenalsin the fight againstvector-borne diseases to save hundreds of millions of lives. Consequently, in the last decade we have attained a remarkable success to combat with many diseases particularly malaria due to the combined effect of indoor residual spraying (IRS) and long-lasting insecticidal nets (LLINs). Currently, malaria mortality rates have drastically fallen by more than $25 \%$ globally, $33 \%$ in sub-Saharan Africa and over a million lives have been saved attributable to massive scale-up of LLINs and IRS. Since, both LLINs and IRS are cost-effective and robust form of interventions; they are serving as a central pillar in the National Malaria Control Programmes (NMCPs) of malaria endemic countries. Nevertheless, LLINs are easy-to-deliver, most economical and practical even in the resource-poor settings, where implementation of IRS is not feasible. The heavy reliance, recurrent and inappropriate insecticide applications are key sources for resistance which is a potential threat to the global public health. Therefore, it has to be addressed immediately to sustain the recent success of vector control, unless otherwise it would become uncertain.

Conclusions: Though, development of resistance is an evolutionary phenomenon, it can be tackled judiciously by implementing appropriate and comprehensive resistance monitoring and management strategies within the framework of integrated vector management. This scrutiny recommends the following measures; (i) identification of effective novel tools for monitoring and evaluation,(ii)searching for alternative interventions to minimize the further resistance evolution as well as to preserve the efficiency of existing insecticides, (iii) exploration of next generation vector control tools in terms of nets and new classes of non-pyrethroid insecticide formulation with new mode of action, (iv) building partnership by bringing together the people actively engaged in the vector control, like public health experts, policy-makers, researchers, medical entomologists and insecticide manufacturers, could ideally pave the way to collectively address the current debacle in the near future.
\end{abstract}

Keywords: Pest Control; Disease Vectors; Mosquito Control; Insecticide Resistance

Copyright $@ 2013$, DocS.; Published by DocS

Article type: Review Article; Received: 17 Dec 2012, Revised:16 Feb 2013, Accepted: 25 Feb 2013;

-Implication for health policy/practice/research/medical education:

The content and results of the present review article helps to identify in detail about the insecticide resistance, existing challenges and perspectives in terms of vector control. The outcome could be useful for the policy/decision makers in order to employ potential vector control measures to minimize the vector-borne diseases burden and for eventual elimination as well as eradication in the near future.

Please cite this paper as:

Karunamoorthi K, Sabesan S. Insecticide Resistance in Insect Vectors of Disease with Special Reference to Mosquitoes: A Potential Threat to Global Public Health. Health Scope. 2012;2(1): 4-18. DOI: 10.17795/jhealthscope-9840

Copyright (๔) 2013, Health Promotion Research Center.

This is an Open Access article distributed under the terms of the Creative Commons Attribution License (http://creativecommons.org/licenses/by/3.0), which permits unrestricted use, distribution, and reproduction in any medium, provided the original work is properly cited. 


\section{Context}

\subsection{Vector-Borne Diseases: A Global Burden}

Despite several decades of control effort, arthropodborne diseases are still regarded as a major public health problem in the tropical and subtropical regions of the world. They are more common in the developing as well as resource-poor countries and inflict enormous burden in terms of morbidity and mortality. Regrettably, the majority of victims are from the pitiable underprivileged members of society. Besides the heightened health impact, they also contribute to extensive poverty, underdevelopment and school absenteeism and dropout etc. These diseases are also responsible for huge economic losses both in terms of health-care costs and loss of productivity, mostly in countries that can least afford them (1).

The uncontrolled population growth in many areas has led to extensive deforestation, irrigation, and unplanned urbanization. These high population densities and associated environmental modifications have created conditions that favor the proliferation of certain arthropod vectors (2). Vector-borne diseases are responsible for $17 \%$ of the global burden of parasitic and infectious diseases. They result in preventable ill-health and death, economic hardship for affected communities, and are a serious impediment to economic development (3). More than a billion people, primarily in developing countries, are now at the risk of contracting such diseases like malaria, filariasis, leishmaniasis, onchocerciasis, trypanosomiasis, dengue, yellow fever, Japanese encephalitis, Plague, the relapsing fevers, and various rickettsial diseases (4).

In the 21st century, the emergence and re-surgence of vector-borne diseases still constitute an important threat to human health, causing over a million death and considerable mortality and morbidity worldwide. Indeed global warming is a major environmental driving force, which directly as well as indirectly attributes to entomological and epidemiological issues for disease transmission. It also influences the frequency and transmission dynamics of infectious diseases. In addition, it may play a pivotal role in sustaining the transmission cycle between vectors and human hosts by the re-emergence of vectors, increased man-vector contact and parasite exposure to diverse strains. Therefore at the moment, control of vector-borne diseases is becoming a great challenge, demanding for novel as well as innovative approaches (5).

\subsection{Vector Control: A Friend in Need to Save Lives}

Vector control is defined as measures of any kind, directed against vectors of diseases and intended to limit their ability to transmit diseases. Over the past several decades, vector control has remained as one of the most powerful weapons in the battle against vector-borne diseases. Even today, it is considered as a corner stone in the malaria control and elimination campaigns, under the specific set of environmental conditions. It is indeed extremely helpful to manage vector populations to reduce/ interrupt disease transmission cycle (6).

Insecticides are considered to be a powerful weapon or silver bullets in the developing countries in order to enhance the agriculture productivity and considerably to improve the major public health indices too (7). They remain as the mainstay in most of the vector control programmes and are commonly applied against adult insects through indoor residual sprays, fumigants, space sprays and treated bed nets. Insecticides are highly effective when optimally implemented $(8,9)$, nevertheless the compounding factors such as inadequate resources and operational capability (10), insecticide resistance (11), and the use of adulterated or poor-quality insecticides (12), may all combine to reduce their efficiency.

There is overwhelming evidence that insecticide treated nets (ITNs) have enormous potential to alleviate the unbearable burden of malaria in Africa and rest of the world. Furthermore, the efficiency of ITNs can be improved by retreatment with insecticides (13). Indeed, insecticides are one of the most potent arsenals in the fight against many vector-borne diseases, particularly malaria. IRS has historically proved to be effective during the Global Malaria Eradication Campaign (1955-1969) in most hitherto malaria endemic countries and over the past several decades, it has been serving as an important component in the National Malaria Control Programmes (NMCPs) in most of the malaria endemic countries (14). IRS is playing a vital role to reduce the prevalence of vector, by minimizing the population/life span and disease incidence considerably. However, it is important to note that the real success of an IRS programme heavily depends upon the quality of the spray (15). Indeed, the current malaria control heavily relies on one class of insecticides, the pyrethroids. The accumulating evidence clearly suggests that genes responsible for resistance to pyrethroid insecticides have been spreading rapidly and are now widespread in African malaria vector mosquitoes. There is ample evidence that at least some of these genes have the potential to threaten the effectiveness of current malaria vector control interventions (16).

Figure 1 clearly shows the evidence of accumulation of malaria vector resistance to commonly used insecticides in several malaria endemic countries worldwide, including Côte d'Ivoire (17), South Africa (18), Burkina Faso (19), Ghana (20), Equatorial Guinea (21), Angola (22), Gabon (23), Benin (24), Ethiopia (25) and Congo-Brazzaville (26). The emergence of resistance may jeopardize the current vector control efforts. Hence, knowledge of vector resistance and changing trends of resistance in target vector species are the basic elements to guide insecticide selection and use in the vector control programmes (27). 


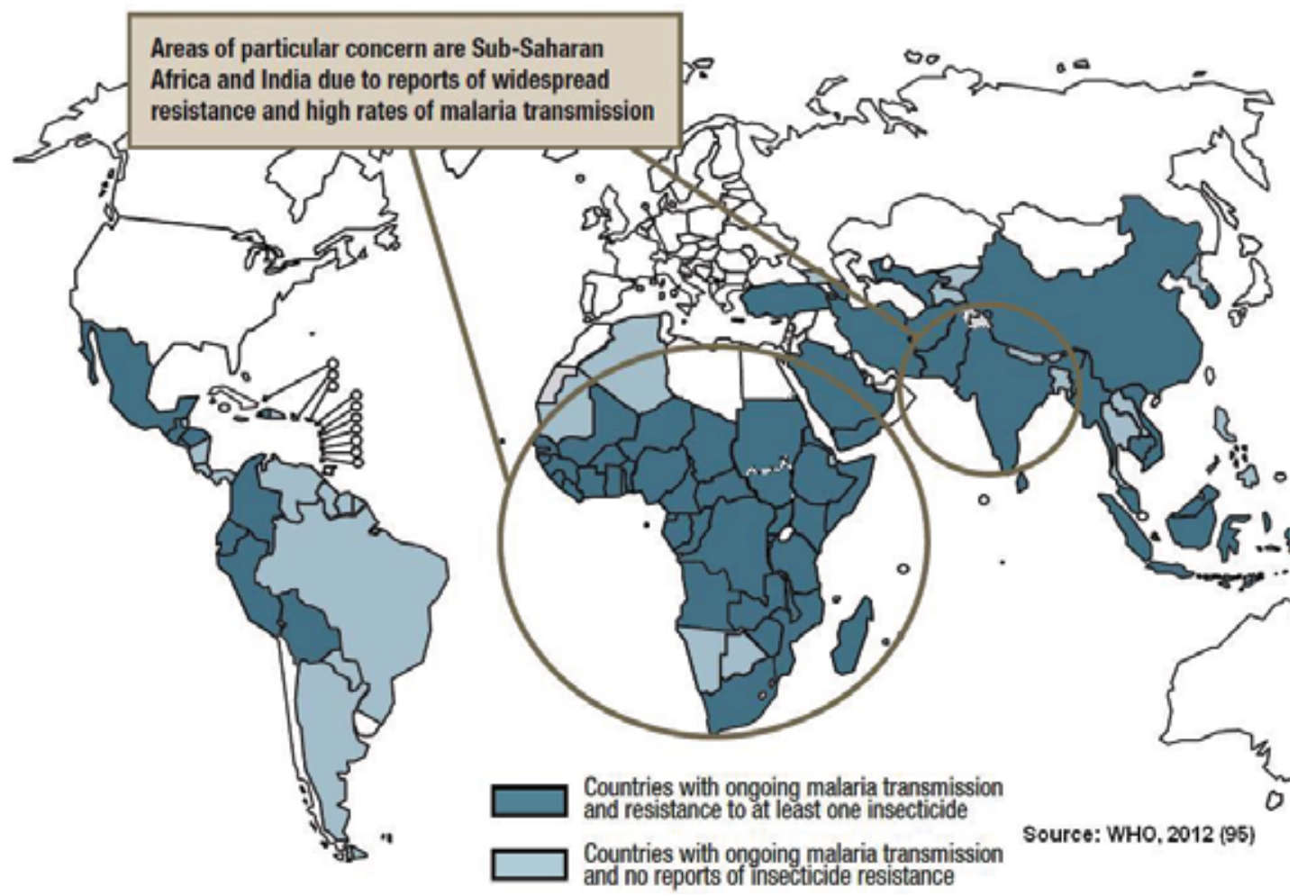

Figure1. CountriesWith Ongoing Malaria Transmission Where Insecticide Resistance has Been Identified in at Least One of Their Major Vectors

Though the insecticide resistance has been reported in several insect vectors of disease, the present scrutiny gives a special emphasis on the impact of insecticide resistance among the Anopheles mosquitoes, due to the public health importance of malaria related illness worldwide particularly in the resource-limited settings.

It is important to note that there are fairly adequate numbers of literature available, however the present communication describes on the current status of insecticide resistance and knowledge of resistance management practices. In this perspective, the present scrutiny becomes more significant and pertains. The outcome of the present scrutiny could pave the way to bring together all the stakeholders actively engaged in vector control programmes such as the researchers, public health experts, medical entomologist and policy makers, to develop appropriate and comprehensive resistance assessment and management techniques in order to collectively find an amicable solution to address the existing global public health issue of insecticide resistance in the future.

\section{Evidence Acquisition}

In order to collect appropriate research materials for the present scrutiny, a detailed search on Scopus, Medline, Google Scholar and Academic Search Premier Databases has been carried out for the period of 1955-
2012. A Boolean search strategy was adopted and the key words entered for search were "insecticide resistance", "insecticide resistance management", "insect resistance development", "impact of insecticide resistance" "insecticide resistance in mosquitoes" "resistance management in mosquitoes" and "cross insecticide resistance" in differing orders, in order to extract studies. Only articles, notes and reviews were chosen, and their bibliographic details (authors, title, full source, document type and addresses) were downloaded to a file for this narrative review.

\subsection{Insecticide: A Powerful Weapon - Silver Bullet}

Insecticide-based vector control interventions are serving as the mainstay to minimize the vector-borne disease burden throughout the world (14). Almost all malaria vector control programs overly rely on either IRS or LLINs. Though much effort has been made to introduce environmental, biological, and immunological methods of control, chemical insecticides are essential to most of the vector-borne disease control programs, especially where no alternative means of preventing transmission of the disease are available (28). At the moment, insecticides belonging to different groups viz., organochlorines, organophosphates, carbamates and synthetic pyrethroids are widely used for various vector control programmes. Some of the key terms related to insecticide resistance have been listed in text box 1(Table 1). 


\begin{tabular}{|c|c|}
\hline Insecticide & Insecticide is a toxic substance that kills insects or eliminates disease-transmitting pests/vectors \\
\hline $\begin{array}{l}\text { Insecticide Resis- } \\
\text { tance }\end{array}$ & $\begin{array}{l}\text { It is a heritable, statistically defined decrease in sensitivity to a chemical in a pest population relative to } \\
\text { the response of susceptible populations that have never been exposed to pesticides. It is the natural abil- } \\
\text { ity of a biotype of an organism to survive exposure to a pesticide that would normally kill an individual } \\
\text { of that species. }\end{array}$ \\
\hline Cross Resistance & $\begin{array}{l}\text { It refers to a type of resistance in which a pest population develops resistance to more than one pesticide } \\
\text { within a chemical family (e.g., organophosphate insecticides, EBDC fungicides, etc.). }\end{array}$ \\
\hline Multiple Resistance & $\begin{array}{l}\text { It involves multiple, independent resistance mechanisms, which often lead to resistance to chemicals } \\
\text { from different families (i.e., organophosphate and carbamate insecticides, dodine and DMI fungicides). }\end{array}$ \\
\hline Metabolic Resistance & $\begin{array}{l}\text { It is a resistance mechanism involving detoxification enzymes that can catalyse the biotransformation } \\
\text { of xenobiotics into metabolites that are less or non-toxic to the organism. }\end{array}$ \\
\hline Resistance Cost & $\begin{array}{l}\text { Resistant individuals have lower fitness levels than do sensitive individuals in the absence of the xenobi- } \\
\text { otic, thus implying a cost of resistance. }\end{array}$ \\
\hline $\begin{array}{l}\text { Insecticide Resis- } \\
\text { tance Management }\end{array}$ & It is an effort to slow down or prevent the development of resistance. \\
\hline $\begin{array}{l}\text { Insecticide Combina- } \\
\text { tion }\end{array}$ & $\begin{array}{l}\text { The use of two or more insecticide applications within a building, e.g. one insecticide on the walls and } \\
\text { another on nets in the same household. Insecticide combinations differ from insecticide mixtures in } \\
\text { that the same insect is likely, but not guaranteed, to come in contact with both insecticides. }\end{array}$ \\
\hline Insecticide Mixture & $\begin{array}{l}\text { Two or more compounds are mixed within a single product or formulation so that the mosquito is guar- } \\
\text { anteed to come into contact with both at the same time. }\end{array}$ \\
\hline Insecticide Mosaic & $\begin{array}{l}\text { The spraying of compound } A \text { in one area and compound B in another area, so that some mosquito popu- } \\
\text { lations are exposed to A while others are exposed to B. }\end{array}$ \\
\hline Synergist & $\begin{array}{l}\text { A substance which does not itself have insecticidal properties, but which, when mixed or applied with } \\
\text { insecticides of a particular class, considerably enhances their potency, for example by inhibiting an } \\
\text { enzyme that normally has detoxifying activity against the insecticide. }\end{array}$ \\
\hline
\end{tabular}

\subsection{Mode of Action of Insecticide}

In General, the mode of action of an insecticide on insect is shown diagrammatically in Figure 2. When insecticides are applied on insects, the active principle reaches the target sites as follow; (i) an insecticide active molecules quickly infiltrates through the integument (the outer layer or cuticle) of an insect, (ii) it reaches the site of action, (iii) insecticide molecules bind with the action site, which may be a vital enzyme, nerve tissue, or receptor protein and eventually (iv) when they have attained threshold concentrations they cause the insect's death.

\subsection{Insecticide Resistance: A Global Threat to Public Health}

According to WHO (1957) (29) resistance has been defined as "the developed ability in a strain of insects to tolerate doses of toxicant which would prove lethal to majority of individuals in a normal population of the same species". Insecticide resistance is the major threat to effective prevention and control of malaria (30). More than 40 years of intensive organic synthetic insecticide use to control arthropod pests and disease vectors have resulted in pesticide resistance among over 450 species (31). The indiscriminate and injudicious use of pesticides has led to the widespread development of resistance.

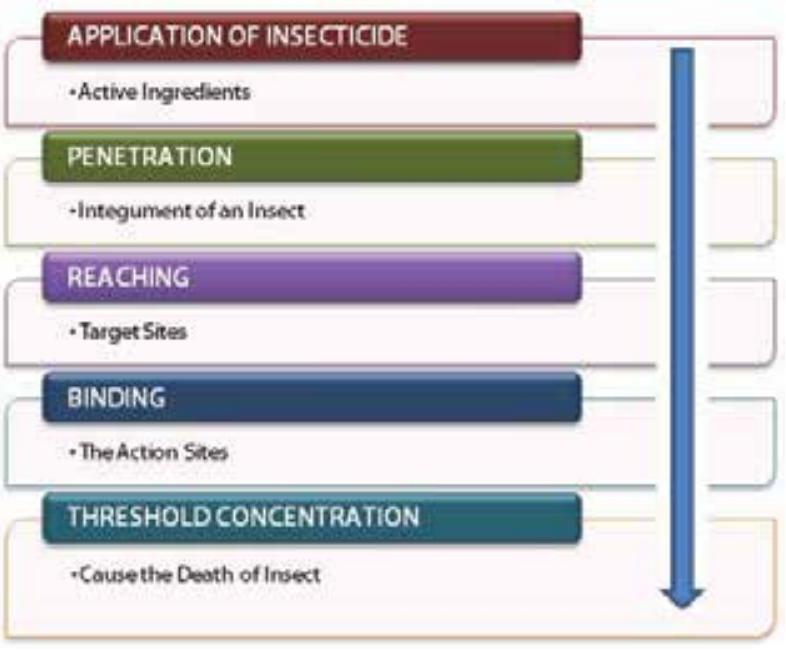

Figure 2. Mode of Action of an Insecticide on Insect

Some insects' species have shown multiple resistances to all classes of insecticide, making their control by means of chemical methods to be extremely difficult and expensive. The number of insecticide-resistant arthropods of public health importance has been observed to rise from 2 in 1946 to 150 in 1980 and 198 in 1990 (32).

A recent study from India has reported that Culexqui- 
nquefasciatus is highly resistant to DDT, malathion, and an incipient resistance to synthetic pyrethroids (deltamethrin, cyfluthrin, permethrin, and lambda cyhalothrin) (33). The situation in Burkina Faso is emblematic with Anopheles gambiae populations showing high levels of resistance to most of the existing synthetic insecticides (34).

In India, six primary vectors of malaria are observed, which include An. culicifacies, An. stephensi, An. fluviatilis, An. minimus, An. dirus and An. sundaicus. In addition to these, An. annularis, An. philippinensis, An. varuna and An. jeyporiensis have also been reported as secondary malaria vectors. An. culicifaciess.l., the major vector in most parts of the country, has been observed to develop with widespread resistance to DDT, dieldrin/ $\mathrm{HCH}$, and also to Malathion in several districts. Other vectors that are reported to be resistant to both DDT and dieldrin/HCH in India are An. stephensi, An. annularis, and An. Philppinensis(35). In India, the recent susceptibility studies reveals that both $A n$. stephensi and An. subpictus species exhibited variable degree of resistance to DDT and Malathion. Larvae of both the species showed some evidence of resistance to chlorpyriphos followed by fenthion too (36).

The resistance usually occurs due to insecticide detoxification by mutant enzymes (isozymes) engendered by resistant gene alleles, but some resistance may also be conferred by the reduced toxicant uptake. The rapid development of resistance to dichlorodiphenyltrichloroethane (DDT) and organophosphates (OPs) is well documented (37). Resistance also arises through the over-use and/or misuse of a pesticide against a pest species and results from the selection of resistant forms of the pest and the resulting evolution of populations become resistant to that pesticide and its mode of action (38). In 1984, the Insecticide Resistance Action Committee (IRAC) was formed in order to provide a coordinated private-sector response to prevent or at least delay the development of resistance (32). It facilitates communication, awareness on insecticide resistance and also promotes the development of resistance management guidelines for sustainable agriculture and enhanced public health (39).

Over the past several decades, the induction of modern synthetic insecticides in the vector control programme has led to the selection pressure on insect populations. It has caused many species of insects, particularly vector of diseases to evolve resistance against various commonly used insecticides (40). At the moment, it has been reported that there is a widespread resistance to all classes of existing insecticides among many insect pests of agricultural and public health importance, making their control more arduous than ever before. In China, all the seven major mosquito vectors have developed resistance to at least three of the four existing classes of insecticides (41). It is important to note that not only mosquitoes, but also the other public health important insects such as fleas, ticks, cockroaches, bedbugs, sand flies, and houseflies evolved insecticide resistance (39), due to their permanent exposure.

\subsection{The Mechanisms of Insecticide Resistance}

There are four major forms of resistance mechanisms described on the biochemical basis; (i) altered target-site resistance, which occurs when the insecticide no longer binds with its targets, (ii) metabolic resistance that occurs due to the modified activities of three major enzyme groups such as esterases, oxidases, or glutathione S-transferases (GST) which inhibit the insecticides from reaching their potential target sites. The resistant insects may possess overproduction of detoxification enzymes that break-down the toxic insecticides into non-toxic compounds, (iii) behavioral resistance occurs when the resistant insects avoid the insecticide treated surface area by changing their customary behavior. For instance the An. arabiensis mosquito has changed its resting behavior from endophilic (resting indoor) nature to exophilic (resting outdoor) in order to avoid the contact or exposure to indoor residual spray in Africa. (iv) Penetration resistance occurs when the cuticle (outer layer of insects) absorb the insecticides molecules much more slowly than the susceptible insects. In addition, the mechanism on thermal stress response has also been proposed by Patil et al. (1996) (42), but its significance has not been wellestablished.

\subsection{The Biochemical Resistance Mechanisms on the Molecular Level}

\subsubsection{Knockdown Resistance ( $k d r$ )}

Pyrethroids are one of the most broad-spectrum insecticides and are commonly applied to control virtually all arthropods in terms of agricultural and medically important concern. It is a large class of structurally very diverse, synthetic analogues of natural pyrethrins from the plant of Chrysanthemum spp. extracts. The insecticide resistance mechanism of pyrethroid is known as knockdown resistance $(\mathrm{kdr})$ resulting from mutations in the voltage-gated sodium channel (the target-site for DDT and pyrethroids) (43). Although many insecticide resistance mechanisms are hitherto proposed, the $\mathrm{kdr}$ and metabolic resistance due to insecticide-detoxification are considered to be the most significant mechanisms.

(A)Single amino acid mutation in the IIS6 membranespanning region of the voltage-gated sodium channel gene confers with the target site DDT-pyrethroid resistance in $A n$. gambiae. The similar type of mutated codon produces resistance to a number of diversified insects such as mosquitoes, sand flies, cockroaches, and flies (Figure 3).

(B)The regulatory element termed the Barbie Box al- 
lows induction of insecticide detoxifying enzymes like oxidase and esterase resistance genes (Figure 3).

(C)Esterase A2-B2 alleles (amplicons). An amplicon is a piece of DNA or RNA that is the source of replication process, which produce one or more copies of a genetic fragment. These resistance esterase genes lie 5 ' end to 5 ' end within the same amplification unit. It has been estimated that nearly more than 100 copies of this amplicon may be present within a single species of mosquito (26) (Figure 3).

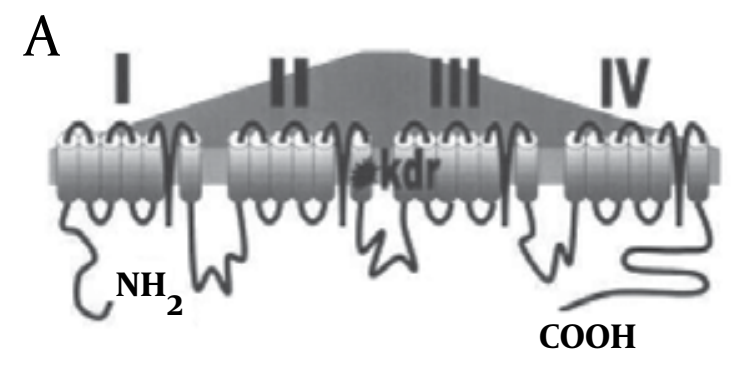

B

\section{5' - ATCAAAAGCTGGAGG -3'}

C

B2

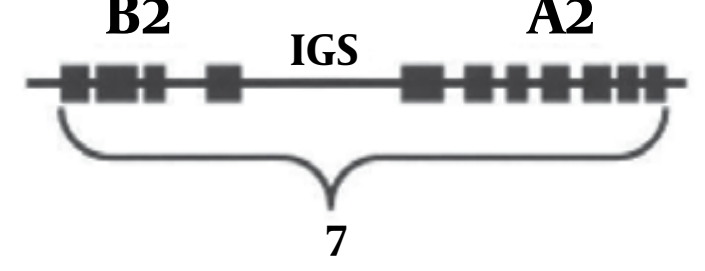

Source: Patil et al., 1996 (42) KB

Figure 3. The Bio-Chemical Resistance Mechanisms on the Molecular Level

\subsection{Three PrincipalTypes ofResistanceMechanisms}

Three types of résistance mechanisms are clearly illustrated in Figure 4(44); the circle represents a cross section of an insect, whereas the left side represents a susceptible and the right denotes a resistant insect. Resistance may happen at each step of this pathway; (i) the integument/ outer-layer (cuticle) of an insect may be altered into a lesser permeable, thus reducing the entry rate/amount of insecticide; (ii) new or more abundant metabolic enzymes may be selected, which break down the insecticide active ingredients more efficiently and make it ineffective; and (iii) alter the target sites - as a result insecticide molecules are no longer able to bind with action sites. Among the types of resistance mechanisms, metabolism and action site insensitivity are the most important types. However, it is important to note that a reduction in the rate of cu- ticular penetration fosters both types of mechanisms in a more synergistic way $(45,46)$.

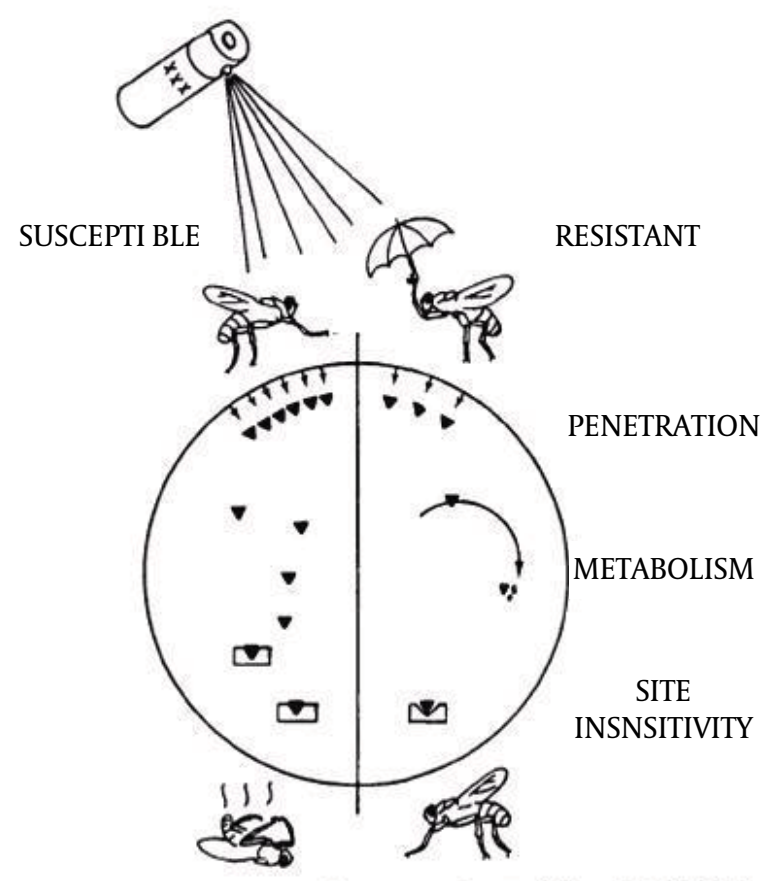

Source: Georghiou $1987(46)$

Figure 4. The Three Principal Types of Insecticide Resistance Mechanisms in Cross SectionThrough Susceptible and Resistant Insects

\subsection{Insect Resistance Development (IRD)}

The natural selection by an insecticide allows some initially rare naturally occurring pre-adapted insects with resistance genes, to survive and pass the resistance trait on to their progenies. The continuous application of insecticides with similar mode of action, results in the selection of the resistant individuals and hence resistance gradually increases among insect population which eliminates the susceptible ones. The resistant insects may multiply more rapidly than the susceptible ones, when the selection pressure continues to be constant, it directly indicates that the insecticide is no longer effective(47).

Mosquito control has focused on the use of insecticides (initially organochlorines, followed by organophosphates and carbamates) through indoor residual spraying. By 1990, more than 500 species of insects and mites had developed resistance to one or more classes of insecticides (44). The use of ITNs for both individual and collective protection against malaria has shown potential in reducing childhood malaria morbidity by $50 \%$ and global mortality by $20-30 \%$ in the Gambia, Ghana, and Kenya (48$50)$. The insecticides of choice for bed net impregnation 
are pyrethroids because of their high efficacy, rapid rate of knockdown, strong mosquito excito-repellent properties, and low mammalian toxicity (51). The recommended doses of pyrethroids for mosquito net treatment pose little or no hazard to people treating the nets or to users of the treated nets. Even the frequent exposure to lower concentrations of pyrethroids, the risk of toxicity is remote (52).

\subsection{Risk Factors Associated With Insect Resistance Development (IRD)}

The most important aspect in terms of selection pressure on public health important insect species is purely due to the availability of limited number of insecticides. To date, only four classes of synthetic insecticides such as organochlorines (now banned in many countries), organophosphates, carbamates and pyrethroids are available to control adult mosquitoes (53). Furthermore, it is important to note that these four classes of insecticides have only two different modes of action to kill the insects. Consequently there is much less target-site diversity among the public health important insect vectors than the pests of agriculture $(54,55)$.

Since insecticides are poison in nature, they must be used very cautiously and deliberately- not indiscriminately. Indeed, the quality vector control programmes must ensure the quality assurance in terms of minimizing the unnecessary insecticide selection pressure in non-endemic areas, which may considerably reduce the avoidable operational costs too (56). It is well established that resistance does not evolve at the same rate in every species or population. Résistance may develop rapidly in some populations and slowly in some others. Selections in the laboratory under seemingly similar conditions, mainly on house flies and mosquitoes, have shown varying propensities for résistance to different insecticides. Resistance evolved most rapidly to higher levels toward the pyrethroid permethrin and most slowly toward the toxin complex of Bacillus thuringiensis subsp. israelensis (BTI) (57).

Several biotic and non-biotic factors have contributed to the evolution of insecticides, factors such as rapid reproduction of insects, migration, existence of susceptible populations, host range, the effective dosage of insecticides, the period and number of applications of insecticides (47). However, it is interesting to note that the development of insecticide resistance is observed to be quite enormous under greenhouses due to their rapid reproduction potential, lack of migration of susceptible insects and the recurrent application of insecticides (47).

In addition, the degree of resistance in insect vector populations is largely dependent both on the volume and frequency of insecticide applications and the inherent nature of the insect species involved. For instance, the tsetse flies (vector of African trypanosomiasis/Sleeping sickness) were controlled by wide-scale spraying of DDT for several years, but so far DDT resistance has never been developed among tsetse flies. Correspondingly, the triatomid bugs (vector of American trypanosomiasis/ Chagas disease) exhibits little or no resistance to insecticides. In both cases, the major influencing factor is their life cycle pattern, especially the long life cycles of triatomid bugs and the production of limited numbers of descendant by the tsetses. In contrast, mosquitoes have all the characteristics suited to rapid insecticide resistance development, including short-span of life cycles with abundant progeny (40). However, in the last decade, various degrees of pyrethroid resistance have been detected in Bolivia, the site of Triatomainfestans origin and dispersal (58), and in some neighboring areas of Argentina (59). In other disease vectors, reduced penetration, increased sequestration, metabolic resistance, and alterations in the target site and behavior modification, are the most widely recognized mechanisms of resistance (60).

\subsection{Cross-Resistance: An Urgent Call for a Tangible Action}

The research on insecticide resistance in insect vector of diseases has mainly focused on insecticides of public health concerns. However, it has been estimated that nearly $90 \%$ of all insecticides worldwide are used for agricultural purposes (61). Therefore, agricultural activities have often been blamed for disease vector of insecticide resistance, but so far only a few attempts have been made to establish the direct impact of agrochemicals. However, Lines (1988) (62) and Georghiou (1990) (63) have reviewed the correlation between agrochemicals and insecticide resistance in mosquito vectors. The insecticide resistance in disease vectors as a result of selection pressure due to agrochemicals have been reported from Central America (64-66), Africa (51), and South Asia (67).

The cross-resistance among different classes of insecticides could substantially impair the usage of existing insecticides due to alterations of target sites or detoxification process. In General, the bio-chemical mechanisms of resistance are primarily associated with either an alteration in the sensitivity of insecticide target site in the central nervous system (sodium channels, gammaaminobutyric acid (GABA) receptors, and acetylcholinesterase) or an increased rate of insecticide detoxification (40). The mechanism of detoxification is also commonly known as metabolic resistance, which primarily involves three major groups of enzymes such as Esterases (ESTs), Glutathione-S-transferases (GSTs), and Mixed Function Oxidases (MFOs) (40). In the recent years, the cross-resistance among the mosquito vectors is a very common phenomenon and well-recorded too. The oxidase-based DDT-pyrethroid cross-resistance has been reported in 
Guatemalan An. albimanus (42) and Kenyan An. gambiae (68), between organophosphates and pyrethroids crossresistance conferred by esterases in An. albimanus (69), and between organophosphates and carbamates in $A n$. albimanus (70). Furthermore, multiple resistances are also well-known and reported among the mosquitoes. It is mainly due to the wide-spread and sequential application of different classes of insecticides to control several species of Anopheles (57, 71).

\subsection{Impact of Insecticide Resistance}

The development of insecticide resistance makes insecticide use ineffective and limits the available vector control options (72), and consequently, resistance is considered as a serious public health issue in the disease control (73). In most of the cases, not only does resistance render the selecting compound much less effective but it also often confers cross-resistance to other chemically inter-related compounds. The striking fact is that the cross-resistance can occur when resistance to one insecticide confers resistance to another insecticide, even where the pest has not been ever exposed to the latter product (38). The medically important insects successfully adapt to most of insecticides by becoming physiologically or behaviorally resistant to them (74) and this creates immense practical problems. Additionally, previous selection with insecticides can confer resistance to new materials through cross-resistance (75-77) and can have serious impacts on control by reducing the effectiveness of many new insecticides.

Strategies to manage resistance have usually been designed after resistance has already been developed. However, if the likelihood of resistance development to novel insecticides can be predicted before they are used; it should be possible to establish an effective resistance management program. Improving our understanding of resistance and cross-resistance mechanisms will therefore enable us to develop a successful program to minimize or prevent further resistance development (78).

Indeed resistance to insecticides by insects is considered as a recent evolutionary adaptation to environmental changes, occurring in less than one century in response to sequential applications of chemical insecticides like organochlorines (OCs), organophosphates (OPs), carbamates and pyrethroids, and even biological insecticides. The emergence of resistance problems not only shortens the lifespan of currently available insecticides but also undermines the efficacy of newly discovered or developed insecticides owing to cross-resistance and multiple resistance mechanisms (41).

In addition, data on insecticide use for vector control are extremely important to design appropriate pesticide management systems on judicious use, resistance management, and reduction of risks to human health and the environment (79). However, a recent global survey drew attention to critical deficiencies in the capacity to manage vector control insecticides. It includes the lack of pesticide registration guidelines, gaps in pesticide procurement practices, and a lack of expertise of vector control decision makers $(80,81)$. These shortcomings could heavily hamper the optimal selection and use of insecticides and application methods for vector control heavily undermine the effectiveness and safety of operations (79).

\subsection{Insecticide Resistance Management (IRM)}

Indeed, there is always a considerable risk of resistance evolution, especially when the insecticides are indiscriminately misused or over-used. The main objective of effective insecticide resistance management programme is to prevent or delay the evolution of resistance, or assist to retrieve the susceptibility status in which insecticide resistance has already been well-established. Since the majority of the insect pest/vector populations are usually larger in size and have the potential for rapid proliferation in terms of shorter life-span with huge number of progeny. For instance a single mosquito can reproduce several thousand progenies within a couple of weeks(38).

Over the past decades, a considerable progress has been made in terms of our knowledge and understanding regarding the biochemistry of résistance and its dynamics in field populations. Indeed, no single prescription can be offered to forestall resistance under any conditions. There are hundreds of different insect pest species that are under chemical control, and each species represents several distinct combinations of biological and ecological characteristics. Management by moderation should be the basic approach and should be supplemented to the maximum possibly by integrated pest management measures (45).

Interestingly, there are several different strategies that have been proposed to tackle the insecticide resistance crisis. The World Health Organization (WHO) strongly recommends the simultaneous use of different vector control tools and this has formulated the basis for Integrated Vector Management (IVM) strategies (82). Indeed, IVM is a rational decision-making process to optimize the use of resources for vector control. The main objective of the IVM approach is to contribute to the achievement of the global targets set for vector-borne disease control, by making vector control more efficient, cost effective, ecologically sound and sustainable with the available tools and resources. In the face of current challenges to vector control, the IVM approach is vital to achieve the national and global targets set for vector-borne disease control (83).

In addition, the rotation of chemically different classes of insecticides has been tested and the use of novel insecticides alone $(84,85)$ or in a mosaic with existing 
insecticides (86) has also been proposed. The early attempts in using entomopathogenic fungi as microbial control agents against insect pests were overshadowed by the development of numerous potential chemical insecticides. However, currently, to address the insecticide resistance by means of biological control agents like the entomopathogenic fungi such as Metarhiziumanisopliae and Beauveriabassiana have also been advocated (87). A recent study demonstrated the importance as well as potentiality of the combination of permethrin and entomopathogenic fungi as vector control interventions against the insecticide-resistant An. gambiae mosquitoes (88). It is important to note that it also exhibited a significant level of synergistic effect on malaria vector mortality and it could prevent or delay the resistance development substantially.

Howard et al. (2010) (89) indicated that the insecticideresistant strains of An. gambiae mosquitoes were more highly susceptible to fungal infection than the insecticide-susceptible strain of An. gambiae. It provides an opportunity to kill insecticide resistant mosquitoes more quickly than the susceptible ones. Therefore, it could serve as one of the ideal tools to tackle the resistance crisis under the field conditions. Furthermore, the entomopathogenic fungal infection may quickly and easily eliminate the insecticide-resistance genes from the wild population and it leaves the susceptible mosquitoes to breed further and this unique phenomenon is extremely important to keep the fungus "evolution-proof" (90). This could lead to an effective resistance management without further application of insecticides. It is one of the most promising techniques, as fungal infection kills the vector mosquitoes at a slower rate than the conventional chemical insecticides.

IRM is used to describe practices aimed at reducing the potential for insect pests to become resistant to a pesticide. Kerr (1963) (91) attributed the resistance development rate to the frequency of resistance genes, the nature of the genes, generational turnover, and the intensity of selection pressure. The first three factors are indigenous to the population and beyond control. Regarding the fourth factor, Georghiou (1980) (92) and Brown (1981) (93) suggested several methods whereby selection pressure might be reduced, and henceforth to postpone the development of resistance. Today, resistance management in the context of integrated pest management has evolved as the favored approach to prevent, delay, or reduce the impact of insecticide resistance. In Colombia, during 2005 and 2006 resistance to pyrethroids and DDT was identified in An. darlingi. Subsequently a quick decision has been made to change to fenitrothion (an organophosphate) with a different mode of action, for IRS. This alternative intervention has removed the selection pressure and reduced the frequency of resistance. As a result, the recent susceptibility tests showed that the frequency of resistance genes in the vector population had dropped below the level of detection, and pyrethroids were once again introduced into the IRS programme, albeit on a more limited scale. It clearly suggests that the resistance genes can be eliminated from the vector population by removing the selection pressure. To fully develop this strategy, a thorough knowledge of insecticide resistance mechanisms is extremely essential.

\subsection{Insecticide Resistance Monitoring and Sur- veillance}

Resistance monitoring and evaluation are critical elements of vector control programme and their impacts are essential to understand the progress, challenges and success of disease control. It should be an integral part of vector/public health pest control programmes. Knowledge of vector/pest susceptibility to pesticides, changing trends of resistance and their operational implications are the basic requirements to guide pesticide use in vector-borne disease and pest control programmes. This information provides a basis to select pesticide(s), ascertain continued susceptibility and efficacy of pesticide(s) in use, and manage vector/pest pesticide resistance.

If, resistance is once established in a vector population, there is a genuine threat of the resurgence of vectorborne diseases that had been presumed to be under control and by the time such resistance is detected, it is often far too late. Therefore, focusing on continuous insecticide resistance surveillance and monitoring is extremely essential to react proactively (39). Indeed, bioassays are the primary tool for the resistance monitoring, but they must be supplemented by molecular and biochemical assays wherever resistance is detected (56).

\subsection{Necessity of Skilled Medical Entomologist}

Vector control can be targeted against larvae and adults of insect vectors and it may differ in countries and even regions within the same country. Therefore, it must be selected more cautiously by considering the existing epidemiological and entomological tools like susceptibility status, population dynamics, vectorial capacity, feeding preference, and major disease transmission season of local insect vectors to sustain in the long-run. The evaluation of existing entomological indicators and/or the development of new indicators can be carried out by the skilled/trained medical entomologist. It could serve as a valuable tool to predict the transmission potential, and selection of practical operational tools for planning and management of vector control programmes, tailor-made for local settings.

However, currently, the lack of entomological capacity 
in vector control programmes is one of the major hindrances to implement effective insecticide resistance monitoring and surveillance in malaria control. Therefore, it is extremely important in all National Malaria Control Programmes (NMCPs) to establish capacity for basic entomological monitoring, by appointing senior medical entomologists or train entomologists wherever necessary, and establish the necessary infrastructure for basic entomological surveillance. In addition, adequate fund also must be allotted to establish the necessary capacity for the vector control programme (56).

\subsection{Development of Next Generation Green Pesti- cides/Risk-Reduced Pesticides}

At the moment, people are appreciating and insinuating the use of plant-based insecticides as pest control agents to control insect vectors and pests. It has ceased the tendency of heavy reliance on chemical insecticides to reduce negative impacts on human health and the environment (94). Although, the usage of plant-based pesticides is a part of tradition and culture in the developing countries, over the past three decades there has been a tremendous dedication and commitment to develop plant-based ideal pesticides or green pesticides by various researchers. As a result we have evaluated over thousands of plants as potential pest control agents in terms of insecticidal, antifeedant, repellent, oviposition deterrent, growth regulatory and antivector activities. However, only a few plant-derived botanicals such as neem, lemon grass, etc have demonstrated their broad effectiveness against various insects. Therefore, development of next generation vector control tools is extremely important particularly formulating new plant-based insecticides in terms of cost-effective, user-environmental friendly with new mode of action.

\subsection{Insecticide Resistance in Mosquitoes}

Malaria is a disease of poverty inflicting a serious negative impact on health and socioeconomic development in the poorest countries of the world that cannot afford to succeed (95). Presently we have minimized the global malaria burden considerably, by inducting the low-cost interventions like ITNs. Control of the vector mosquitoes has been an integral part of efforts to either eliminate or control the disease worldwide. In West Africa, where the main vectors are members of the An. gambiae complex and the An. funestus group, various attempts were made to control malaria, by use of insecticides, from the early 1930s until the 1960s. In West Africa, resistance to pyrethroids due to knockdown resistance (kdr) mutations in An. gambiae populations has been reported in Côte d'Ivoire $(96,97)$, Burkina Faso and Benin (98) despite the absence of large-scale mosquito control in these countries. Resistance of An. gambiae, the main malaria vector in West Africa, to pyrethroids poses a great challenge to the strategy of using insecticide-treated materials for malaria control. The number of available and effective pesticides for malaria vector control is also reported to be decreasing. Currently, only the pyrethroid class of insecticides is appropriate for ITNs impregnation and LLINs (30). However, vectors developing resistance against pyrethroid is already a serious threat to sustain the continuous use of ITNs and IRS. Although 12 insecticides are currently recommended by the WHO for IRS, they belong only to four different chemical classes namely organochlorines, pyrethroids, carbamates, and organophosphates, and the cross-resistance among insecticides is often frequent.

The widespread use of the same insecticides in the agricultural sector has made the situation worse. Resistance may develop due to changes in the mosquito's enzyme systems, resulting in more rapid detoxification or sequestration of the insecticide, or due to mutations in the target site preventing the insecticide-target site interaction (99). Insecticides that can be used in malaria control are becoming increasingly limited. Introduction of inappropriate insecticides without a proper understanding of the prevailing resistance mechanisms may lead to enhanced vector resistance and vector control failure. Early detection and knowledge on the resistance status and the underlying mechanisms in vector mosquitoes are essential for effective long-term control of the vector.

It is obvious that the ongoing malaria vector control strategies heavily rely on the use of IRS and ITNs. The current success of these strategies in reducing the occurrence of malaria, contributed towards the optimism that elimination of this disease which is a major public health problem is a feasible objective. Substantial international efforts have been made for the last three years enabling access to approximately 289 million ITNs in sub-Saharan Africa, enough to cover $76 \%$ of the 765 million people at the risk of malaria. The number of countries that employed IRS as vector control strategy has increased from 31 in 2007 to 68 in 2009 (56).

In Africa, LLINs and IRS are now being deployed in a large-scale more than ever before, which considerably exposes African vectors to enormous selection pressure for insecticide resistance. Unfortunately, since the introduction and commercialization of the pyrethroids in the 1970s and 1980s, little public investment has been observed in insecticides for public health purposes. Therefore, the majority of this selection pressure comes from the pyrethroid insecticides. These are the only class of insecticides currently applied to treated nets and most 
commonly used for IRS application (56).

Therefore the widespread as well as indiscriminate usage of pyrethroid insecticide increases the risk of resistance. The situation may be accelerated by the reintroduction of DDT in several countries of Africa as crossresistance between these classes of insecticides which can occur as a result of amino acid substitutions in the shared target sites. All major malaria vectors in Africa have developed resistance to these insecticides and the resistance alleles appear to be spreading at an exceptionally rapid rate (16). Inheritable resistance traits develop by selective pressure exerted on a mosquito population. Fast-acting insecticides exert strong selection pressures, and the short generation time and prolific progeny characteristic of the mosquito lifecycle is well suited for quick development of resistance. Over 50 species of Anopheles are reported to be resistant to insecticides (40).

Insecticide resistance in the vector Aedesaegypti is an important but under research, and poorly understood phenomenon. Several early reports of DDT resistance, in the 1960 s to 1980 s, reported cross-resistance between DDT and pyrethroids. Later literature suggests that organophosphate resistance is also developing in some areas. The impact of this resistance on operational activities such as larviciding and space spraying is largely unknown. Resistant populations of Aedesaegypti have been detected in several countries throughout the geographical range of this species and, in some areas; the evolution of insecticide resistance has been linked to the failure of the dengue control programme. Very little is known about the molecular or biochemical basis of this resistance and yet such information is needed to identify the origin of resistance and develop suitable strategies to reduce its spread and minimize the impact of resistance mutations.

\subsection{Resistance Management in Mosquitoes}

Certainly, IRS programmes should avoid the practice of spraying the same class of insecticide repetitively year after year. Instead, another opportunity is to spray insecticides with different modes of action alternately and alternating different insecticides in space, as a mosaic in rotation , (56). Rotations are common forms of 'best practice' in agriculture, and are considered to have a good record in slowing down the evolution of resistance. Combination of interventions involves using different insecticide classes applied in different forms within a house (e.g. a carbamate sprayed on the wall and a pyrethroid on an LLIN). In the case of larval control, there is only one which is currently recommended, organophosphate, temephos, which could be used in rotation or as a spatial mosaic with other larvicidal agents (30). Therefore, such combinations are likely to play a vital role in the future insecticide resistance management programmes (56).
It is important to understand that almost all public health insecticide classes are also used in agriculture and it substantially contributes to some degree of the resistance problem in malaria vectors. In the developing countries farmers obtain insecticide from the public health personals engaged in the indoor residual spraying and use for agricultural pest control. For example in Ethiopia, although DDT has been totally banned for agriculture pest control, a recent study reported that DDT has been extensively applied by the farmers as a pesticide, which has been procured illicitly through the black market at a low-cost (7).

\section{Results}

The evolution of high gene frequencies of resistance is most commonly associated with IRS. It is interesting to note that numerous numbers of insecticides are currently available in the market for agricultural pest control rather than malaria vector control. Therefore, the agricultural sector has many choices for the selection of various kinds of appropriate insecticides and must avoid using the insecticides of public health importance. It is desirables for both the agriculture and public health sectors to work together for sustainable insecticide resistance management. However, it demands further research to understand the influence of different agricultural and domestic pesticide uses on emergence and spread of insecticide resistance which are important to public health (56).

Currently there is a lack of alternative, cost-effective and safe insecticides. The development of new, alternative insecticides is a high priority, but is an expensive and longterm endeavor. Indeed, it is essential that novel alternative insecticides belonging to new or different classes be developed if current scaling-up efforts are to be sustained and if local interruption of malaria transmission is to be achieved. Above all, new classes of insecticides with novel mode of actions are urgently needed; especial insecticide products are suitable for use on bed nets. Furthermore, it is also essential to preserve and prolong the susceptibility and effectiveness or life of the currently available insecticides, which will involve new formulations designed for resistance management (56).

In the recent years, an encouraging progress has been made to develop insecticides with new active ingredients to manage insecticide resistance. Innovative Vector Control Consortium (IVCC) (100) has already developed an impressive pipeline for reformulations of existing insecticides, and the ongoing search for new active ingredients is promising. The new formulation makes the insecticide more effective on more challenging surfaces, such as traditional mud used in house building in rural African communities, and reduces IRS programme costs by increasing the required interval between applications. The new formulation not only increases the residual per- 
formance of the insecticide, but also provides an effective tool to control pyrethroid resistant mosquitoes in the field. But greater investments are urgently required to speed up the research and development process (100)

Besides, promoting appropriate and alternative ecofriendly vector control technologies like use of botanical pesticides may reduce the use of hazardous insecticides (5) as well as minimize the insecticide resistance in the future. Otherwise, the recent advances will be rapidly jeopardized, especially in the case of indoor residual spraying, which tends to lose its efficacy as soon as vectors become resistant.

At present, malaria control relies heavily on a limited arsenal: artemisinin derivatives and pyrethroids. However, these could also become ineffective, owing to the development of resistance. In this perspective, innovative user-friendly and environment-friendly alternatives to conventional vector control are apparently inevitable. The exploration and development of novel and powerful contextual community-based vector control interventions are also warranted. Continuous effort is extremely needed in terms of research and development to develop next generation vector control tools as well as to improve the existing interventions, such as vector control, diagnosis, treatment, vaccines, bio-control of vectors, environmental management, and surveillance, for the sustainable elimination of malaria and possible eventual eradication in the near future (6).

\section{Conclusions}

Insect-borne diseases such as malaria, filariasis, Leishmaniasis, onchocerciasis, trypanosomiasis, dengue, yellow fever and Japanese encephalitis are not only existing as a major health issue but also as a foremost cause of poverty. Insecticides remain as the most important element of vector control programmes. However, the present scrutiny clearly suggests that many insect vectors of diseases have evolved a widespread resistance to the key classes of insecticides, particularly, pyrethroids used for effective vector control. The potentiality of the existing insecticides must be preserved by reducing further resistance, unless otherwise insecticide resistance could be a potential threat to global public health. In fact, it is a global and evolutionary phenomenon which calls for stringent efforts to sustain the effectiveness, by avoiding resistance problems to promote the development of appropriate resistance management strategies.

The management of Insecticide resistance can be achieved by various means and they are suggested in terms of the following strategies; (i) better knowledge on vector susceptibility status to insecticides (ii) continuous and careful resistance monitoring and surveillance in order to understand the current threat and evolution of insecticide resistance (iii) understanding the varying trends of resistance (iv) appropriate usage of biochemi- cal or molecular techniques for resistance detection (v) implementation of appropriate insecticide resistance management practices to preserve insecticide susceptibility (vi) elimination of resistance genes from the vector population by removing the selection pressure (vii) reduction of heavy reliance of chemical insecticides to slow down the evolution of resistance (viii) searching for next generation vector control tools (ix) exploration of non-pyrethroid formulations with unique novel modes of action for LLINs and IRS. ( $x$ ) Building the partnership by bringing all the stakeholders actively engaged in the vector control programmes like public health experts, researchers, medical entomologist, policy makers, individuals and insecticide manufacturers, to pave the way to address the current disaster, in the near future. We are both hopeful and optimistic that addressing the challenges posed by insecticide resistance could be an initial foot step to create a world that is free from the scourge of vector-borne diseases.

\section{Acknowledgements}

Authors would like to thank Mrs. Melita Prakash for her sincere assistance in editing the manuscript. They would like to thank both anonymous reviewers for their constructive comments as well as suggestion to improve this manuscript substantially. The last but not the least heartfelt thanks go to the colleagues of the Department of Environmental Health Science, College of Public Health and Medicine, Jimma University, Jimma, Ethiopia, for their kind support and cooperation.

\section{Authors' Contribution}

KK oversaw the initial literature search and review; identified additional literature and data published world-wide. KK and SS contributed to the conception and writing of this manuscript and approved the final version. KK is guarantor of the paper.

\section{Financial Disclosure}

None declared.

\section{Funding/Support}

Nil.

\section{References}

1. Jacobs-lorena M, James AA. Genetic modification of insects of medical importance: past, present and future.Report of the Scientific Working Group on Insect Vectors and Human Health, TDR/SWG/VEC/03.1. 2002:68-73

2. Service MW. Agricultural development and arthropod-borne diseases: a review. Rev Saude Publica. 1991;25(3):165-78

3. WHO . WHO position statement on integrated vector management. WHO/HTM/NTD/VEM/2008.2.2008;

4. Pant C. Vector borne diseases of man and their socio-economic impact. Insect Sci. Applic. 1987;8:655-664

5. Karunamoorthi K. Impact of Global Warming on Vector-Borne Diseases: Implications for Integrated Vector Management. J So- 
cialomics. 2012;1(e113)

6. Karunamoorthi K. Vector Control: A Cornerstone in the Malaria Elimination Campaign. Clin Microbiol Infect. 2011;17(11):1608-1616

7. Karunamoorthi K, Mohammed M, Wassie F. Knowledge and practices of farmers with reference to pesticide management: implications on human health. Arch Environ Occup Health. 2012;67(2):109-16

8. Lengeler C. Insecticide-treated nets for malaria control: real gains. Bull World Health Organ. 2004;82(2):84

9. Mabaso ML, Sharp B, Lengeler C. Historical review of malaria control in southern African with emphasis on the use of indoor residual house-spraying. Trop Med Int Health. 2004;9(8):846-56

10. Kleinschmidt I, Torrez M, Schwabe C, Benavente L, Seocharan I, Jituboh D, et al. Factors influencing the effectiveness of malaria control in Bioko Island, equatorial Guinea. Am J Trop Med Hyg. 2007;76(6):1027-32

11. Cohen C, Pickworth WB, Henningfield JE. Cigarette smoking and addiction. Clin Chest Med.1991;12(4):701-10

12. Amount of poor-quality pesticides sold in developing countries alarmingly high [media release]. Rome/Geneva: Food and Agricultural Organization of the United Nations/World Health Organization; 2001. 2009; Available from: http://www.fao.org WAICENT/OIS/PRESS_NE/PRESSENG/2001/pren0105.htm.

13. Karunamoorthi K, Mengistie E, Dagnew Z, Deboch B. Examining household possession and willingness to pay for the retreatment of ITNs with insecticides among local residences in a malaria endemic area. East Afr J Pub Health. 2010;7(4):313-318

14. Karunamoorthi K, Yirgalem A. Insecticide Risk Indicators and Occupational Insecticidal Poisoning in Indoor Residual Spraying. Health Scope. 2012;1(3):118-126

15. Vector resistance to pesticides. Fifteenth Report of the WHO Expert Committee on Vector Biology and Control. World Health Organ Tech Rep Ser. 1992;818:1-62

16. Ranson H, N'Guessan R, Lines J, Moiroux N, Nkuni Z, Corbe $\mathrm{V}$. Pyrethroid resistance in African anopheline mosquitoes: what are the implications for malaria control? Trends Parasitol. 2011;27(2):91-8

17. Martinez-Torres D, Chandre F, Williamson MS, Darriet F, Berge JB, Devonshire AL, et al. Molecular characterization of pyrethroid knockdown resistance ( $\mathrm{kdr}$ ) in the major malaria vector Anopheles gambiae s.s. Insect Mol Biol. 1998;7(2):179-84

18. Hargreaves K, Koekemoer LL, Brooke BD, Hunt RH, Mthembu J, Coetzee M. Anopheles funestus resistant to pyrethroid insecticides in South Africa. Med Vet Entomol. 2000;14(2):181-9

19. Diabate A, Baldet T, Chandre F, Dabire KR, Simard F, Ouedraogo $\mathrm{JB}$, et al. First report of a kdr mutation in Anopheles arabiensis from Burkina Faso, West Africa. I Am Mosq Control Assoc. 2004;20(2):195-6

20. Yawson AE, McCall PJ, Wilson MD, Donnelly MJ. Species abundance and insecticide resistance of Anopheles gambiae in selected areas of Ghana and Burkina Faso. Med Vet Entomol. 2004;18(4):372-7

21. Reimer LJ, Tripet F, Slotman M, Spielman A, Fondjo E, Lanzaro GC An unusual distribution of the kdr gene among populations of Anopheles gambiae on the island of Bioko, Equatorial Guinea. Insect Mol Biol. 2005;14(6):683-8

22. Cuamba N, Choi KS, Townson H. Malaria vectors in Angola: distribution of species and molecular forms of the Anopheles gambiae complex, their pyrethroid insecticide knockdown resistance (kdr) status and Plasmodium falciparum sporozoite rates. Malar J. 2006;5:2

23. Pinto J, Lynd A, Elissa N, Donnelly MJ, Costa C, Gentile G, et al. Co-occurrence of East and West African kdr mutations suggests high levels of resistance to pyrethroid insecticides in Anopheles gambiae from Libreville, Gabon. Med Vet Entomol. 2006;20(1):27 32

24. Pinto J, Lynd A, Vicente JL, Santolamazza F, Randle NP, Gentile $\mathrm{G}$, et al. Multiple origins of knockdown resistance mutations in the Afrotropical mosquito vector Anopheles gambiae. PLoS One 2007;2(11)

25. Balkew M, Ibrahim M, Koekemoer LL, Brooke BD, Engers H, Aseffa
A, et al. Insecticide resistance in Anopheles arabiensis (Diptera: Culicidae) from villages in central, northern and south west Ethiopia and detection of kdr mutation. Parasit Vectors. 2010;3(1):40

26. Kaiser ML, Koekemoer LL, Coetzee M, Hunt RH, Brooke BD. Stag gered larval time-to-hatch and insecticide resistance in the major malaria vector Anopheles gambiae S form. Malar J. 2010;9:360

27. Van Bortel W, Trung HD, Thuan le K, Sochantha T, Socheat D, Sumrandee $\mathrm{C}$, et al. The insecticide resistance status of malaria vectors in the Mekong region. MalarJ. 2008;7:102

28. Gratz NG, Jany WC. What role for insecticides in vector control programs? Am JTrop Med Hyg. 1994;50(6 Suppl):11-20

29. WHO (World Health Organization). Technical Report Series No 125,1957 ; Insecticides seventh report of the expert committee.

30. USAID . Integrated Vector Management Programs for Malaria Control. Programmatic Environmental Assessment. Bureau for Global Health, United States Agency for International Development, RTI International, Durham, NC, United States of America 2007;

31. Georghiou GP. The magnitude of the resistance problem. In Glass EH, editor. Pesticide resistance: Strategies and tactics for management. 1986;

32. WHO. Pesticides and their application. WHO/CDS/NTD/WHOPES/ GCDPP/2006.1. World Health Organization, Switzerland. 2006; Available from: http://whqlibdoc.who.int/hq/2006/WHO_CDS NTD_WHOPES_GCDPP_2006.1_eng.pdf.

33. Kumar K, Sharma AK, Kumar S, Patel S, Sarkar M, Chauhan LS Multiple insecticide resistance/susceptibility status of Culex quinquefasciatus, principal vector of bancroftian filariasis from filaria endemic areas of northern India. Asian Pac J Trop Med 2011;4(6):426-9

34. Namountougou M, Simard F, Baldet T, Diabaté A, Ouédraogo JB et al. Multiple Insecticide Resistance in Anopheles gambiae s.l. Populations from Burkina Faso, West Africa. PLoS ONE. 2012;7(11)

35. Mittal PK, Wijeyaratne P, Pandey S. Status of Insecticide Resistance of Malaria, Kala-azar and Japanese Encephalitis Vectors in Bangladesh, Bhutan, India and Nepal (BBIN). Environmental Health Project. 2004; Available from: .

36. Tikar SN, Mendki MJ, Sharma AK, Sukumaran D, Veer V, Prakash S, et al. Resistance status of the malaria vector mosquitoes, Anopheles stephensi and Anopheles subpictus towards adulticides and larvicides in arid and semi-arid areas of India. J Insect Sci. 2011;11:85

37. Rawlins SC, Wan JO. Resistance in some Caribbean populations of Aedes aegypti to several insecticides. J Am Mosq Control Assoc. 1995;11(1):59-65

38. Bellinger RG. Pesticide Resistance Management. 2011; Available from: http://www.clemson.edu/extension/rowcrops/pest/ files/2011pmhpest_resist_mgmt.pdf..

39. Nauen R. Insecticide resistance in disease vectors of public health importance. Pest Manag Sci. 2007;63(7):628-33

40. Hemingway J, Ranson H. Insecticide resistance in insect vectors of human disease. Annu Rev Entomol. 2000;45:371-91

41. Cui F, Raymond M, Qiao CL. Insecticide resistance in vector mosquitoes in China. Pest Manag Sci. 2006;62(11):1013-22

42. Patil NS, Lole KS, Deobagkar DN. Adaptive larval thermotolerance and induced cross-tolerance to propoxur insecticide in mosquitoes Anopheles stephensi and Aedes aegypti. Med Vet Entomol. 1996;10(3):277-82

43. Brogdon WG, McAllister JC, Corwin AM, Cordon-Rosales C. Oxidase-based DDT-pyrethroid cross-resistance in Guatemalan Anopheles albimanus. Pesticide Biochem Physiol.1999;64:101-111

44. Georghiou GP, Green HM, LeBaron , Moberg WK. Overview of insecticide résistance. Managing résistance to agrochemicals from fundamental research to practical strategies. In: Georghiou GP, Green HM, LeBaron , Moberg WK, editors.American Chemical Society Symposium Series 42.Washington, DC:1990. p. 18-41

45. Georghiou GP. Principles of insecticide resistance management Phytoprotection. 1994;75(4):51-59

46. Hrncir Z, Salavec M, Tichy M, Vavrina J. Humoral immunity of synovial fluid. Sb Ved Pr Lek Fak Karlovy Univerzity Hradci Kralove. 1977;20(1):1-103 
47. IRAC . Resistance Management for Sustainable Agriculture and Improved Public Health. Available from: http://www.irac-online. org/about/resistance..

48. Alonso PL, Lindsay SW, Armstrong JR, Conteh M, Hill AG, David $\mathrm{PH}$, et al. The effect of insecticide-treated bed nets on mortality of Gambian children. Lancet. 1991;337(8756):1499-502

49. Binka FN, Kubaje A, Adjuik M, Williams LA, Lengeler C, Maude $\mathrm{GH}$, et al. Impact of permethrin impregnated bednets on child mortality in Kassena-Nankana district, Ghana: a randomized controlled trial. Trop Med Int Health. 1996;1(2):147-54

50. Nevill CG, Some ES, Mung'ala VO, Mutemi W, New L, Marsh K, et al. Insecticide-treated bednets reduce mortality and severe morbidity from malaria among children on the Kenyan coast. Trop Med Int Health. 1996;1(2):139-46

51. Diabate A, Baldet T, Chandre F, Akoobeto M, Guiguemde TR, Darriet $\mathrm{F}$, et al. The role of agricultural use of insecticides in resistance to pyrethroids in Anopheles gambiae s.l. in Burkina Faso. Am JTrop Med Hyg. 2002;67(6):617-22

52. Zaim M, Aitio A, Nakashima N. Safety of pyrethroid-treated mosquito nets. Med Vet Entomol. 2000;14(1):1-5

53. Zaim M, Guillet P. Alternative insecticides: an urgent need. Trends Parasitol. 2002;18(161-163)

54. Nauen R, Bretschneider T. New modes of action of insecticides. Pesticide Outlook. 2002;13:241-245

55. Nauen R. Insecticide mode of action: return of the ryanodine receptor. Pest Manag Sci. 2006;62(8):690-2

56. WHO. The technical basis for coordinated action against insecticide resistance: preserving the effectiveness of modern malaria vector control: WHO Geneva, Meeting report. . 2011;

57. Georghiou GP, Green MB, LeBaron HM, Moberg WK. Overview of insecticide resistance. In: Georghiou GP, Green MB, LeBaron HM, Moberg WK, editors.Managing resistance to agrochemical.Washington DC: American Chemical Society; 1990. p. 18-41

58. IRAC . Resistance Management for Sustainable Agriculture and Improved Public Health. Available from: http://www.irac-online. org/about/resistance.

59. Panzera F, Dujardin JP, Nicolini P, Caraccio MN, Rose V, Tellez T, et al. Genomic changes of Chagas disease vector, South America. Emerg Infect Dis. 2004;10(3):438-46

60. Orihuela PL, Vassena CV, Zerba EN, Picollo MI. Relative contribution of monooxygenase and esterase to pyrethroid resistance in Triatoma infestans (Hemiptera: Reduviidae) from Argentina and Bolivia. J Med Entomol. 2008;45(2):298-306

61. Ranson H, Claudianos C, Ortelli F, Abgrall C, Hemingway J, Sharakhova MV, et al. Evolution of supergene families associated with insecticide resistance. Science. 2002;298(5591):179-81

62. WHO . Resistance of vectors and reservoirs of disease to pesticides. WHO Technical Report Series . 1986;737:1-87

63. Lines JD. Do agricultural insecticides select for insecticide resistance in mosquitoes? A look at the evidence. Parasitol Today. 1988;4(7):S17-20

64. Georghiou GP, Roush RT, Tabashnik BE. The effect of agrochemicals on vector populations. In: Georghiou GP, Roush RT, Tabashnik BE, editors.Pesticide resistance in arthropods.New York: Chapman and Hall; 1990. p. 183-202

65. Georghiou GP, Ariaratnam V, Breeland SG. Anopheles albimanus: development of carbamate and organophosphorus resistance in nature. Bull World Health Organ. 1971;46:551-554

66. Chapin G, Wasserstrom R. Agricultural production and malaria resurgence in Central America and India. Nature. 1981;293(5829):181-5

67. Brogdon WG, Beach RF, Stewart JM, Castanaza L. Microplate assay analysis of the distribution of organophosphate and carbamate resistance in Guatemalan Anopheles albimanus. Bull World Health Organ. 1988;66(3):339-46

68. Sharma VP. Re-emergence of malaria in India. Indian J Med Res. 1996;103:26-45

69. Ranson H, Jensen B, Vulule JM, Wang X, Hemingway J, Collins FH Identification of a point mutation in the voltage-gated sodium channel gene of Kenyan Anopheles gambiae associated with resistance to DDT and pyrethroids. Insect Mol Biol. 2000;9(5):491-7
70. Brogdon WG, Barber AM. Fenitrothion-deltamethrin cross-resistance conferred by esterases in Guatemalan Anopheles albimanus. Pesticide Biochem Physiol.1990;3:130-139

71. Hemingway J, Georghiou GP. Studies on the acetylcholinesterase of Anopheles albimanus resistant and susceptible to organophosphate and carbamate insecticides. Pesticide Biochem Physiol. 1983;19:167-171

72. Brogdon WG, McAllister JC. Insecticide resistance and vector control. Emerg Infect Dis. 1998;4(4):605-13

73. WHO . Test procedures for insecticide resistance monitoring in malaria vectors; bio-efficacy and persistence of insecticides on treated surfaces. 1998;

74. Rivero A, Vezilier J, Weill M, Read AF, Gandon S. Insecticide control of vector-borne diseases: when is insecticide resistance a problem? PLoS Pathog. 2010;6(8)

75. Sawicki RM, Denholm I. Adaptation of insects to insecticides. Ciba Found Symp. 1984;102:152-66

76. Golenda CF, Forgash AJ. Fenvalerate cross-resistance in a resmethrin-selected strain of the house fly (Diptera: Muscidae).J Econ Entomol.1985;78(1):19-24

77. Scott JG. Cross-resistance to the biological insecticide abamectin in pyrethroid-resistant house flies. Pesticide Biochem Physiol. 1989;34:27-31

78. Bisset J, Rodriguez M, Soca A, Pasteur N, Raymond M. Cross-resistance to pyrethroid and organophosphorus insecticides in the southern house mosquito (Diptera:Culicidae) from Cuba. J Med Entomol.1997;34(2):244-6

79. Liu H, Cupp EW, Micher KM, Guo A, Liu N. Insecticide resistance and cross-resistance in Alabama and Florida strains of Culex quinquefasciatus [correction]. J Med Entomol. 2004;41(3):408-13

80. van den Berg H, Zaim M, Yadav RS, Soares A, Ameneshewa B, Mnzava A, et al. Global trends in the use of insecticides to control vector-borne diseases. Environ Health Perspect. 2012;120(4):577-82

81. Matthews G, Zaim M, Yadav RS, Soares A, Hii J, Ameneshewa B, et al. Status of legislation and regulatory control of public health pesticides in countries endemic with or at risk of major vectorborne diseases. Environ Health Perspect. 2011;119(11):1517-22

82. van den Berg H, Hii J, Soares A, Mnzava A, Ameneshewa B, Dash $\mathrm{AP}$, et al. Status of pesticide management in the practice of vector control: a global survey in countries at risk of malaria or other major vector-borne diseases. Malar J. 2011;10:125

83. WHO. Global strategic framework for integrated vector management. WHO/CDS/CPE/PVC/2004.10. World Health Organization,. 2004;

84. Handbook for Integrated Vector Management. WHO/HTM/NTD/ VEM/2012.3.2012; Available from: .

85. Asidi AN, N'Guessan R, Hutchinson RA, Traore-Lamizana M, Carnevale P, Curtis CF. Experimental hut comparisons of nets treated with carbamate or pyrethroid insecticides, washed or unwashed, against pyrethroid-resistant mosquitoes. Med Vet Entomol. 2004;18(2):134-40

86. N'Guessan R, Boko P, Ogjo A, Knols B. Control of pyrethroid-resistant Anopheles gambiae and Culex quinquefasciatus mosquitoes with chlorfenapyr in Benin. Trop Med Int Health. 2009:14:1-7

87. Hougard JM, Corbel V, N'Guessan R, Darriet F, Chandre F, Akogbeto $M$, et al. Efficacy of mosquito nets treated with insecticide mixtures or mosaics against insecticide resistant Anopheles gambiae and Culex quinquefasciatus (Diptera: Culicidae) in Cote d'Ivoire. Bull Entomol Res. 2003;93(6):491-8

88. Farenhorst M, Mouatcho JC, Kikankie CK, Brooke BD, Hunt RH, Thomas MB, et al. Fungal infection counters insecticide resistance in African malaria mosquitoes. Proc Natl Acad Sci U S A. 2009;106(41):17443-7

89. Farenhorst M, Knols BG, Thomas MB, Howard AF, Takken W, Rowland $\mathrm{M}$, et al. Synergy in efficacy of fungal entomopathogens and permethrin against West African insecticide-resistant Anopheles gambiae mosquitoes. PLoS One. 2010;5(8)

90. Howard AF, Koenraadt CJ, Farenhorst M, Knols BG, Takken W. Pyrethroid resistance in Anopheles gambiae leads to increased susceptibility to the entomopathogenic fungi Metarhizium anisopliae and Beauveria bassiana. Malar J. 2010;9:168 
91. Read AF, Lynch PA, Thomas MB. How to make evolution-proof in secticides for malaria control. PLoS Biol. 2009;7(4)

92. Kerr RW. Some recent advances in the study of insecticide resistance. J Aust Inst Agric Sci.1963;29:31-37

93. Brown TM. Countermeasures for insecticide resistance. Bull Entomol Soc Am. 1981;27:198-201

94. Karunamoorthi K. Medicinal and Aromatic Plants: A Major Source of Green Pesticides/Risk-Reduced Pesticides. Med Aromat Plants. 2012;1:137

95. Karunamoorthi K. Global Malaria Burden: Socialomics Implications. J Socialomics. 2012;1:108

96. Elissa N, Mouchet J, Riviere F, Meunier JY, Yao K. Resistance of Anopheles gambiae s.s. to pyrethroids in Cote d'Ivoire. Ann Soc Belg Med Trop. 1993;73(4):291-4
97. Chandre F, Darriet F, Manguin S, Brengues C, Carnevale P, Guillet P. Pyrethroid cross resistance spectrum among population of Anopheles gambiae s.s. from Cote d'Ivoire. J Am Mosq Control Assoc. 1999;15(1):53-9

98. Chandre F, Manguin S, Brengues C, Dossou Yovo J, Darriet F, Diabate A, et al. Current distribution of a pyrethroid resistance gene (kdr) in Anopheles gambiae complex from west Africa and further evidence for reproductive isolation of the Mopti form. Parassitologia. 1999;41(1-3):319-22

99. Hemingway J, Hawkes NJ, McCarroll L, Ranson H. The molecular basis of insecticide resistance in mosquitoes. Insect Biochem Mo Biol. 2004;34(7):653-65

100. The IVCC Annual Report for 2011 -2012. 2013; Available from: http://www.ivcc.com/. 